\title{
Correction to: From the past to the future: what we learn from China's 2020 Census
}

\section{Zhenzhen Zheng ${ }^{1}$ (1)}

Published online: 17 June 2021

(c) China Population and Development Research 2021

\section{Correction to: China Population and Development Studies https://doi.org/10.1007/s42379-021-00084-8}

The article was accidentally published with an error in the first sentence. It should read:

The results of the seventh national census conducted in 2020 have been released by the National Bureau of Statistics (2021) in May 11, 2021, which unsurprisingly revealed that China's population is in an era of low fertility and aging, and the population growth has almost come to a halt.

This has been corrected and no other changes to the article have been made.

The original article can be found online at https://doi.org/10.1007/s42379-021-00084-8.

Zhenzhen Zheng

zhengzz@cass.org.cn

1 Institute of Population and Labor Economics, Chinese Academy of Social Sciences, Beijing, China

Springer 